\title{
Development of a delayed-release nutrient for appetite control in adults with obesity and type 2 diabetes and initial clinical testing in a single dose randomized controlled trial
}

\author{
E. Beale $\mathbb{D}^{1}$, E. Lim $\mathbb{E}^{2}$, H. Yassine ${ }^{1}$, C. Azen ${ }^{2}$ and C. Christopher ${ }^{3}$
}

\begin{abstract}
Background and objectives: Delivery of nutrients directly to the small intestine, either via enteral feeding tube or by gastric bypass surgery, is associated with increased levels of appetite-suppressing and glucoregulatory hormones, including GLP-1, and reduced appetite. Achieving these changes non-invasively using formulated foods may be of therapeutic benefit in individuals with obesity and related comorbidities. The aim of this pilot study was to determine the effect of a single dose of a novel delayed-release nutrient (DRN) on glucose, GLP-1, c-peptide, insulin, and appetite in adults with obesity and type 2 diabetes.
\end{abstract}

Subjects and methods: We formulated an all-natural, generally recognized as safe ('GRAS") DRN and conducted a randomized prospective crossover trial. Nineteen adults with obesity and type 2 diabetes underwent paired 3-h meal tolerance tests (MTT) in randomized order 1-4 weeks apart. Subjects ingested a single dose of DRN and the same nutrients as unformulated powders (UN).

Results: For DRN compared with UN, the maximal concentration (Cmax) was significantly lower for glucose, c-peptide, and insulin, and the time of maximal concentration (Tmax) was significantly delayed. While Tmax for GLP-1 was also significantly delayed following DRN compared with UN (45 min later; $p=0.26)$, Cmax did not differ significantly. GLP-1 rose significantly during the last $90 \mathrm{~min}$ of the $3-\mathrm{h} \mathrm{MTT}\left(\beta_{1}=0.16 \mathrm{pg} / \mathrm{mL} / \mathrm{min}, p=0.025\right)$, while following UN it decreased $\left(\beta_{1}=-0.21 \mathrm{pg} / \mathrm{mL} / \mathrm{min}, p=0.0026\right)$ ( $p$ difference $=0.0003$ ). There were minimal differences in seven measures of appetite and adverse symptoms between DRN and UN.

Conclusions: We conclude that nutrient can be formulated using all-natural ingredients to induce a delayed rise in GLP-1. Further testing is needed to determine the amount and site of nutrient release, when maximum GLP-1 levels occur, and if modification of the formulation specifications and dose are associated with appetite and glucose control.

Correspondence: E Beale (beale@usc.edu)

${ }^{1}$ Division of Endocrinology and Diabetes, Keck School of Medicine, University of Southern California, Los Angeles, CA 90033, USA

${ }^{2}$ SC CTSI, Keck School of Medicine, University of Southern California, Los Angeles, CA 90033, USA

Full list of author information is available at the end of the article.

\section{Introduction}

Increased distal nutrient delivery is now considered to initiate multiple gut-based neurohormonal pathways, including intestinal L-cell activation, that mediate the metabolic benefit of gastric bypass surgery ${ }^{1-5}$. This proposed key proximal mechanism is corroborated by

\section{(c) The Author(s) 2019}

(c) Open Access This article is licensed under a Creative Commons Attribution 4.0 International License, which permits use, sharing, adaptation, distribution and reproduction cc) in any medium or format, as long as you give appropriate credit to the original author(s) and the source, provide a link to the Creative Commons license, and indicate if changes were made. The images or other third party material in this article are included in the article's Creative Commons license, unless indicated otherwise in a credit line to the material. If material is not included in the article's Creative Commons license and your intended use is not permitted by statutory regulation or exceeds the permitted use, you will need to obtain permission directly from the copyright holder. To view a copy of this license, visit http://creativecommons.org/licenses/by/4.0/. 
numerous studies demonstrating that delivery of nutrient directly to the intestine via enteral feeding tube can acutely and significantly increase GLP-1 as well as other appetite-suppressing gut hormone levels, and increase satiety while reducing net caloric intake ${ }^{6-9}$.

We hypothesized that a formulation designed to release nutrient rapidly in the small intestine would simulate the appearance of nutrient in the small intestine, which occurs after gastric bypass surgery, and with nutrient administration by post-pyloric enteral feeding tube, and thereby increase GLP-1 release ${ }^{10}$. We propose that such a nutrient formulation could be ingested before, or even in place of, a regular meal to reduce appetite and caloric intake and improve glucose control.

As pharmaceutical materials used for delayed-release coatings of drugs and dietary supplements have limits on the amount that can be safely ingested, we investigated using natural polymeric carbohydrate coating materials. These coatings have the added benefit of meeting consumer preference for non-pharmaceutical therapies ${ }^{11}$. Currently, there are few reports of all-natural formulated nutrients for appetite and glucose control, and no commercially available products with demonstrated clinical efficacy $^{12-16}$.

The aim of this pilot clinical trial was to evaluate in obese subjects with type 2 diabetes, the effects of ingestion of a single dose of a novel delayed-release nutrient formulation on circulating levels of GLP-1 and appetite compared with ingestion of the same amount of unformulated nutrient. We also evaluated the effects of this intervention on adverse symptoms and on levels of Cpeptide, insulin, and glucose.

\section{Materials and methods}

\section{Rationale for delayed-release nutrient specifications}

The specifications for the delayed-release nutrient formulation were derived from multiple enteral feeding tube studies demonstrating that satiety and appetite regulating hormones are increased and total caloric intake is decreased through a variety of macronutrients delivered at different rates and sites in the small intestine, as summarized in a recent review by Alleleyn et al. (see Table 1$)^{8}$. We have conducted studies using a mixed macronutrient formulation delivered by enteral feeding tube into the upper small intestine in adults with obesity and type 2 diabetes, and also in non-obese adults with type 1 diabetes. As a result, we identified a site, dose, mixed macronutrient composition, and rate of nutrient delivery that significantly enhanced levels of several glucose- and appetite- regulating hormones (GLP-1, PYY, and insulin), along with satiety ${ }^{6}$.

Based on our work and that of others, we aimed to develop a nutrient formulation that would allow delivery of $\sim 200 \mathrm{kcal}$ of nutrient several times a day for several months directly to the small intestine. Pharmaceutical delayed-release coatings have limits on the amount that can be safely ingested and prohibit their use in the quantities required when coating microparticles in the amounts of nutrient we desired to deliver. By contrast, there are no such limits on the small number of coatings composed of "generally recognized as safe" ("GRAS") materials that have recently become commercially available ${ }^{11,17,18}$. The ethyl cellulose-alginate GRAS coating (Nutrateric ${ }^{\circledR}$ Nutritional Enteric Coating System, Colorcon Harleysville, PA) was selected to provide enteric protection in the acidic $\mathrm{pH}$ of the stomach, while enabling release of nutrient in the alkaline upper intestine without concern for toxicity ${ }^{19}$. The size of the coated pellets was specified to be $<2 \mathrm{~mm}$ to permit free passage across the pylorus $^{20}$. The nutrient was ingested with non-caloric diet tonic water to maintain the integrity of the coating in the acidic stomach without addition of free nutrients to the ingested coated nutrient ${ }^{21}$.

The nutrients (sucrose and whole milk powder) and caloric load (200 kcal) used in the DRN formulation were selected to have a similar composition to those used in our previous studies using a mixed macronutrient liquid formulation (Ensure ${ }^{\oplus}$ Original Nutrition Shake, Abbott) delivered by enteral feeding tube to the upper intestine ${ }^{6,7}$.

\section{Manufacturing of DRN}

The DRN was manufactured for the investigators at a commercial GMP manufacturing facility (Deseret Laboratories, Inc. St George, Utah). Commercially available sugar spheres (Suglets ${ }^{\circledR}$, Colorcon, Harleysville, PA) were spray coated with whole milk powder to $200 \%$ weight gain. These particles were then coated with ethyl cellulose-alginate coating to $15 \%$ weight gain (Nutrateric ${ }^{\circ}$ Nutritional Enteric Coating System, Colorcon Harleysville, PA). Discrete pellets were manufactured such that $99.6 \%$ of particles had a sieve diameter of $<2 \mathrm{~mm}$.

\section{Dissolution Testing of DRN}

In vitro USP dissolution testing was conducted at $37^{\circ} \mathrm{C}$ with paddle stirrers operating at $75 \mathrm{rpm}$ with $\mathrm{pH} 1.2$ (equivalent to empty gastric $\mathrm{pH}$ ) for $1 \mathrm{~h}$ and then $\mathrm{pH}$ of 6.8 (equivalent to small intestinal $\mathrm{pH}$ ) for a further $2 \mathrm{~h}$ (see Fig. 1). Sucrose release was measured on three dissolution tests as $6 \pm 3.8 \%$ at $1 \mathrm{~h}, 24 \pm 7.7 \%$ at $2 \mathrm{~h}$, and $75 \pm$ 9.3\% at $3 \mathrm{~h}$ (Evolution 6100 Dissolution System).

\section{Study design}

This was a prospective randomized crossover trial. Each subject underwent two 3-h meal tolerance tests (MTT) 1-4 weeks apart, once with coating applied to the macronutrient (DRN) and once with unformulated macronutrient, with powdered coating material (UN). As the coating material (Nutrateric ${ }^{\circ}$ ) was not available for 
Table 1 Composition of administered delayed-release nutrient (DRN) and unformulated nutrient (UN)

\begin{tabular}{|c|c|c|}
\hline & Delayed-release nutrient (DRN) & Unformulated nutrient (UN) and coatings \\
\hline Energy (kcal) & 200 & 200 \\
\hline Weight (g) & 50 & 50 \\
\hline $\begin{array}{l}\text { Coating materials } \\
\text { weight ( } \% \\
\text { weight gain) }\end{array}$ & $15 \%$ & $15 \%$ \\
\hline Ethyl cellulose source & $\begin{array}{l}\text { Surelease }{ }^{\circledR} \text { Colorcon Harleysville, PA in commercially available coating } \\
\text { Nutrateric }^{\circledR} \text { Nutritional Enteric Coating System, Colorcon Harleysville, PA }\end{array}$ & $\begin{array}{l}\text { Dietary fiber cellulose, nutricology, } \\
\text { alameda, CA }\end{array}$ \\
\hline Ethyl cellulose (g) & 5.9 & 5.9 \\
\hline Alginate source & $\begin{array}{l}\text { NS Enteric }{ }^{\circledR} \text { Colorcon Harleysville, PA in commercially available coating } \\
\text { Nutrateric }^{\circledR} \text { Nutritional Enteric Coating System, Colorcon Harleysville, PA }\end{array}$ & $\begin{array}{l}\text { Sodium alginate-food grade, distributed by } \\
\text { Landor Enterprises, Inc. Williamsport, PA }\end{array}$ \\
\hline Alginate (g) & 0.7 & 0.7 \\
\hline $\begin{array}{l}\text { Ratio ethyl cellulose: } \\
\text { alginate }\end{array}$ & 90:10 & 90:10 \\
\hline Sucrose source & SUGLETS ${ }^{\circledR}$ Sugar Spheres, Colorcon Harleysville, PA & $\begin{array}{l}\text { SUGLETS }{ }^{\circledR} \text { Sugar Spheres, Colorcon } \\
\text { Harleysville, PA }\end{array}$ \\
\hline Sucrose spheres (g) & 15 & 15 \\
\hline $\begin{array}{l}\text { Sucrose spheres } \\
\text { diameter }(\mu \mathrm{m})\end{array}$ & $850-1000$ & $850-1000$ \\
\hline Sucrose spheres (kcal) & 60 & 60 \\
\hline $\begin{array}{l}\text { Whole milk } \\
\text { powder source }\end{array}$ & $\begin{array}{l}\text { Whole milk powder regular, Fonterra Co-operative Group Limited, } \\
\text { Auckland, New Zealand }\end{array}$ & $\begin{array}{l}\text { Whole milk powder regular, Fonterra Co- } \\
\text { operative Group Limited, Auckland, New } \\
\text { Zealand }\end{array}$ \\
\hline $\begin{array}{l}\text { Whole milk } \\
\text { powder (g) }\end{array}$ & 29 & 29 \\
\hline $\begin{array}{l}\text { Whole milk powder- } \\
\text { Carbohydrate }(\mathrm{g})\end{array}$ & 11.6 & 11.6 \\
\hline $\begin{array}{l}\text { Whole milk powder- } \\
\text { Protein }(\mathrm{g})\end{array}$ & 7.1 & 7.105 \\
\hline $\begin{array}{l}\text { Whole milk powder- } \\
\text { Fat }(\mathrm{g})\end{array}$ & 7.6 & 7.627 \\
\hline $\begin{array}{l}\text { Whole milk powder- } \\
\text { (kcals) }\end{array}$ & 145 & 145 \\
\hline Tonic water source & Schweppes Diet Tonic Water Dr. Pepper Snapple Group, Inc Plano, TX & $\begin{array}{l}\text { Schweppes Diet Tonic Water Dr Pepper } \\
\text { Snapple Group, Inc Plano, TX }\end{array}$ \\
\hline $\begin{array}{l}\text { Volume diet } \\
\text { tonic water }\end{array}$ & 11 & 11 \\
\hline Calories tonic water & 0 & 0 \\
\hline $\mathrm{pH}$ tonic water & 2.5 & 2.5 \\
\hline
\end{tabular}

ingestion as individual ingredients in powder form, commercially available substitutes in equivalent amounts to that used in the DRN were administered for the UN. The order of DRN and UN dosing was determined from a computer-generated randomization list generated by the PI (see Table 1). The research assistant enrolled the subjects and ascertained the order of treatment at the first study visit from sequentially numbered envelopes. 


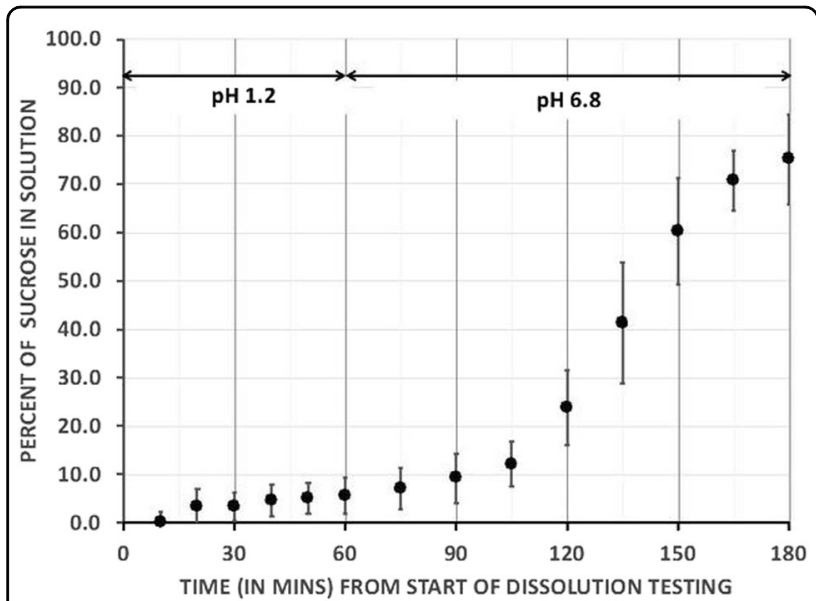

Fig. 1 In vitro dissolution testing. The mean and standard deviation of three dissolution tests performed in vitro show significant increase in percent of sucrose in solution starting in minute 120-180 at pH 6.8

\section{Subjects}

Key inclusion criteria were age 18-65 years, body mass index $>27 \mathrm{~kg} / \mathrm{m}^{2}$, type 2 diabetes with a duration $<10$ years and using only lifestyle modification, metformin, sulfonylureas, thiazolidinedione, or SGLT2 inhibitors for type 2 diabetes management. Key exclusion criteria were known foregut pathology or prior foregut surgery, previous surgical treatment for obesity and a history of pancreatitis. Use of insulin, DPP4 inhibitors or GLP-1 analog inhibitors in the previous 3 months and diet attempts using herbal supplements or over the counter medications in the past 1 month were also criteria for exclusion. Subjects with allergy to dairy products or intolerance to lactose were excluded from participation. The Western Institutional Review Board approved the study protocol. All subjects were screened for eligibility and provided written consent. The study statistician was blinded to the treatment group by use of group numbers in the dataset.

\section{Study visit preparation}

All study visits took place at the University of Southern California Diabetes and Obesity Research Institute. Subjects fasted for $8 \mathrm{~h}$ from the evening before the start of the study visit, omitted their diabetes medications, and avoided vigorous exercise on the morning of their visit. Study visits were started between 8 and $10 \mathrm{am}$. Height, weight, and point of care HbA1c were measured at the first visit. Capillary blood glucose level was tested immediately prior to each MTT and was required to be between $70-200 \mathrm{mg} / \mathrm{dL}$ for the study to proceed.

\section{Study visit}

Subjects reclined quietly on a phlebotomy chair at 45 degrees for the duration of the study without speaking or sleeping and were asked to read, use a computer, or watch non-food related television to occupy their time. They were permitted to get up to use the restroom. A peripheral intravenous line was placed with saline to keep the vein open. Two $4 \mathrm{~mL}$ blood samples were collected $5 \mathrm{~min}$ apart at -5 and 0 min to establish baseline. Immediately afterwards, the subjects were given $50 \mathrm{~g}(200 \mathrm{kcal})$ of DRN or UN, to ingest within 5 min with $235 \mathrm{mls}$ (an $11 \mathrm{fl}$. oz bottle) of room temperature diet tonic water. Study subjects were not blinded to the nutrient being administered but were informed only that any effects of the two nutrients on their appetite or blood results would be compared. DRN was spooned into the mouth and swallowed down with the diet tonic water without chewing on the pellets. UN was mixed with the diet tonic water to create a smooth drink. Blood samples were collected every $15 \mathrm{~min}$ for $3 \mathrm{~h}$.

\section{Visual analog scale}

At each blood draw, satiety, and adverse symptoms were assessed by the study subject using a visual analog scale $^{22-24}$. Subjective feelings of hunger, fullness, satisfaction, and thoughts of food were recorded on a paper scale by marking a $150 \mathrm{~mm}$ line, without reference to previous responses. Nausea, abdominal pain, perspiration, and palpitations were also rated. (See Appendix A).

\section{Blood sample processing and assay}

Samples were drawn into $4 \mathrm{ml}$ EDTA vacutainers prepared with aprotinin (Phoenix Pharmaceuticals, Inc. Catalog \#: RK-APRO): $1 \mathrm{mg} / \mathrm{mL}$ ( $500 \mathrm{KIU} / \mathrm{mL}$ ) of blood and DPP4 inhibitor (Millipore, Catalog \#: DPP4-010): $10 \mathrm{uL} / \mathrm{mL}$ of blood. After collection, samples were mixed by gentle inversion of the tube. The tube was then placed in an ice bath and centrifuged within $1 \mathrm{~h}$ of collection at $1500-2000 \times g(\mathrm{RCF})$, for $15 \mathrm{~min}$ at $4{ }^{\circ} \mathrm{C}$. Plasma (0.5 mls) was aliquoted into each of four cryovials. Cryovials were then immediately frozen and stored upright at $-70^{\circ} \mathrm{C}$ until assay. Batched assay was performed using a Millipore Human Metabolic Expanded Hormone Magnetic Bead Panel (Cat\#HMHEMAG-34K-04, Insulin, C-peptide, GLP-1 (total). Plasma glucose concentrations were determined using an YSI 2300 autoanalyzer (Yellow Springs Instruments, Yellow Springs, $\mathrm{OH}$ ).

\section{Data collection and statistical analysis}

The specific aims of the study were to compare, in obese adult subjects with type 2 diabetes, levels of circulating GLP-1, C-peptide, insulin, glucose, satiety, and any adverse effects following DRN and UN in paired MTTs. The primary outcomes were maximum concentration (Cmax) and area under the curve (AUC) of total GLP-1. Secondary outcomes were Cmax and AUC levels of Cpeptide, insulin, glucose, and the satiety and adverse effect 
scores on MTTs. Cmax is the average of each subject's maximum level of GLP-1 following DRN and UN. Cmin and Tmin were reported for hunger and desire, since they decreased from baseline. In order to determine sample size we used data from two sources to derive mean changes in GLP-1 and the SD of the paired difference: (1) data from our group evaluating paired comparisons of three-hour enteral versus oral mixed meal tolerance tests in obese adults with type 2 diabetes $^{6}$, and (2) data comparing pre-post gastric bypass in non-diabetics ${ }^{25}$. These data yielded a projected effect size of 0.68 (mean GLP-1 paired difference, divided by SD of difference); a sample of 20 participants was required to detect this effect with $80 \%$ power and testing at a 2 -sided alpha of 0.05 . The data were captured in a custom-designed REDCap database ${ }^{26}$. Data were screened, validated, corrected, and summarized prior to analysis for the number of observations, mean, standard deviation, minimum, and maximum for each variable. Random effects mixed models for 2-by-2 crossover designs were used to compare DRN and UN for Cmax, Tmax, AUC final-Initial value and the maximum rise over baseline. Exploratory analysis of slopes was performed by fitting linear regression models for the first and last 90 -min periods for each subject. The resulting slopes were compared using random effects mixed models with interaction between period and time to compare paired differences between the first and the last $90 \mathrm{~min}$ within each treatment and between DRN and UN within each 90-min segment. Since this was conducted as a pilot study, no adjustment was made to $p$-values for the multiplicity of analyses. Statistical analyses were performed using SAS/STAT $\odot$ version 9.2 software, at a 2 -sided 0.05 significance level.

\section{Results}

\section{Study flow and demographics}

Subjects were recruited from February to June 2017 and the study was conducted from March to July 2017. The flow of subjects through the study is shown in Fig. 2. Eighteen subjects were taking metformin, three pioglitazone and two a sulfonylurea. The average fasting capillary blood glucose at the start of each visit was $148.5 \pm$ $34.3 \mathrm{mg} / \mathrm{dL}$. Demographic data of the 19 subjects with paired MTTs included in analysis are shown in Table 2. The trial was completed after recruitment of target enrollment was reached.

\section{Hormone and glucose assays}

The mean (SEM) and mean differences for DRN and UN, 95\% confidence limits and p-values are shown for all hormone and glucose assays in Appendix B.

Following UN, glucose and all hormones peaked in the first $90 \mathrm{~min}$ and this is not reflected in the slope, which is shallow for this period. Thus, only slope comparisons

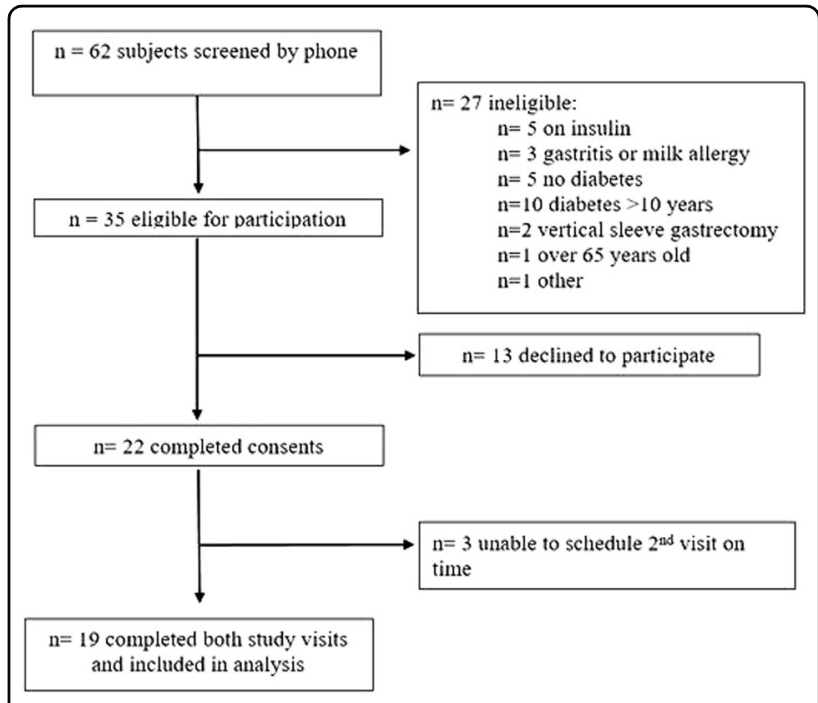

Fig. 2 Subject flowchart. After screening 62 potential subjects by phone, 22 agreed to participate, and completed the consent process. However, due to scheduling difficulties, only a total of 19 subjects completed both study visits

\section{Table 2 Demographics of subjects with paired meal} tolerance tests (MTT)

\begin{tabular}{ll} 
Total subject $(N)$ & 19 \\
Male: female & $7: 12$ \\
Age (years) & $49 \pm 8$ \\
Weight $(\mathrm{kg})$ & $106.7 \pm 27.3$ \\
BMI $\left(\mathrm{kg} / \mathrm{m}^{2}\right)$ & $38.7 \pm 7.5$ \\
HbA1c (\%) & $7.4 \pm 1.4$ \\
Duration with diagnosis of type 2 diabetes (years) & $3.9 \pm 2.5$ \\
\hline
\end{tabular}

within the DRN group between the first and last $90 \mathrm{~min}$, and between UN and DRN in the last $90 \mathrm{~min}$ are presented.

\section{GLP-1}

GLP-1 Tmax occurred later following DRN than following UN (103 mins. vs. 58 mins., $p=0.03)$ and had a greater overall increase over baseline $(11.6 \mathrm{pg} / \mathrm{mL}$ vs. $-8.7 \mathrm{pg} / \mathrm{mL}, p=0.02$ ) (see Fig. 3a). However, Cmax GLP1 levels, was not significantly different between DRN and $\mathrm{UN}$ and AUC for the study period was not was not significantly different between DRN and UN.

The slope of GLP-1 $(\mathrm{pg} / \mathrm{mL} / \mathrm{min})$ increased during the last $90 \mathrm{~min}$ of the 3 -h MTT following DRN $\left(\beta_{1}=0.16\right.$, $p=0.025)$, while it decreased following $\mathrm{UN}\left(\beta_{1}=-0.21\right.$, $p=0.003)$, and these slopes were significantly different $(p=0.0003)$ Within-group comparison of the slope 

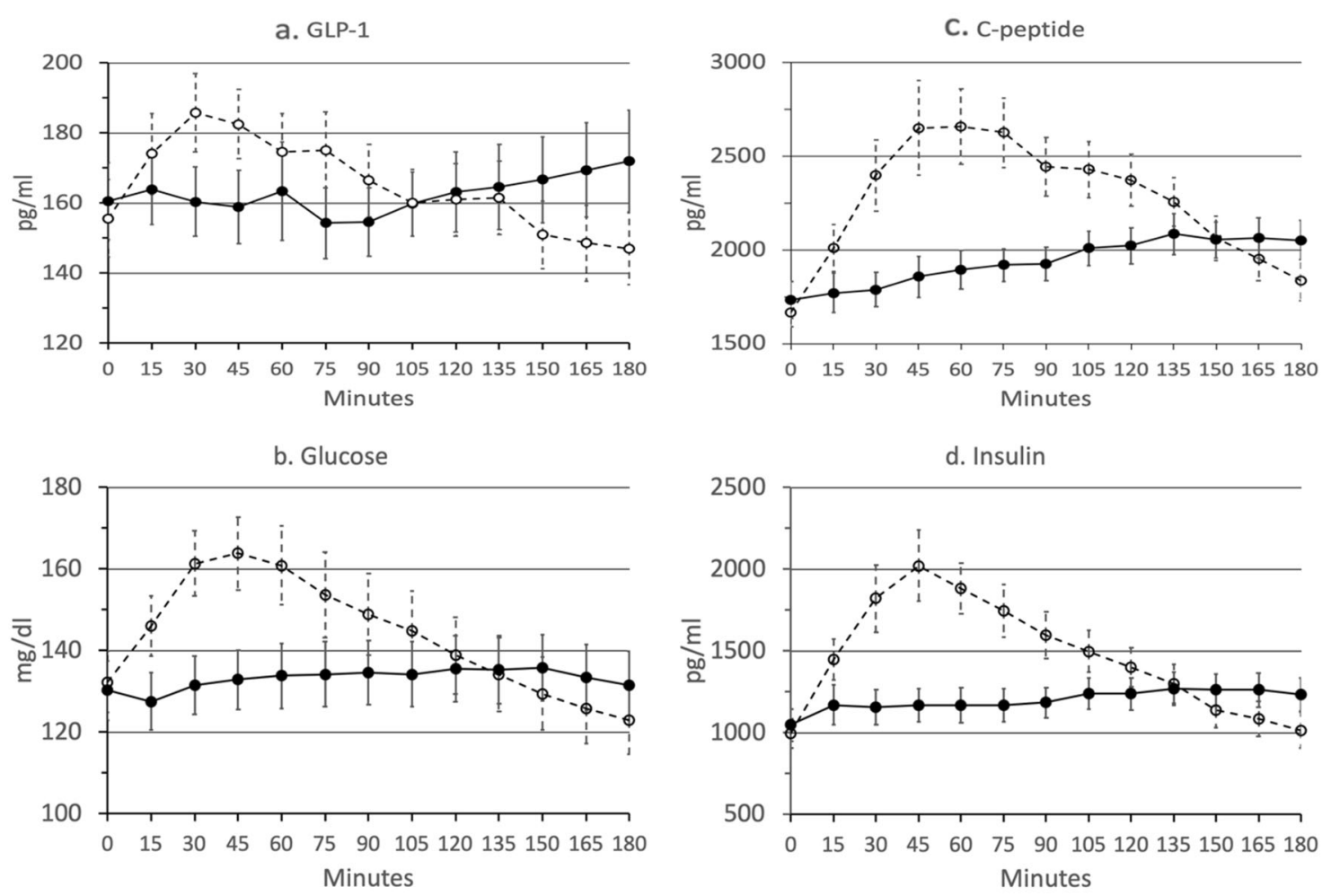

Fig. 3 Average raw values for each analyte during 3-hour MTT ( $\boldsymbol{n}=\mathbf{1 9}$ pairs). Dotted line and open circles represent unformulated nutrient (UN). Solid Line and closed circles represent delayed-release nutrient (DRN). Data points represent mean (SEM) for all DRN and UN at each time point

between the first and last $90 \mathrm{~min}$ of the MTT was significant for DRN $(p=0.017)$.

\section{Glucose}

Glucose Cmax was lower following DRN than following UN $(142 \mathrm{mg} / \mathrm{dL}$ vs. $168 \mathrm{mg} / \mathrm{dL}, p<0.0001)$ and Tmax later following DRN than following UN (84 min. vs. 43 min., $p=0.003$ ), with a lower AUC ( $24 \mathrm{k}$ vs. $26 \mathrm{k}, p=$ $0.018)$, lower maximum rise over baseline $(11.9 \mathrm{mg} / \mathrm{dL}$ vs. $35.3 \mathrm{mg} / \mathrm{dL}, p<0.0001)$, and greater increase over baseline (1.10 mg/dL vs. $-9.41 \mathrm{mg} / \mathrm{dL}, p=0.0009$ ) (see Fig. 3b).

Glucose slopes $(\mathrm{mg} / \mathrm{dL} / \mathrm{min})$ for DRN was positive in the first $90 \mathrm{~min}\left(\beta_{1}=0.07, p=0\right.$. Slopes differed significantly between DRN and UN in the last $90 \mathrm{~min}(p<$ 0.0001). Within-group comparisons of slopes between first and last $90 \mathrm{~min}$ were significant for DRN ( $p=$ 0.0497).

\section{C-peptide}

C-peptide Cmax was lower following DRN than following UN (2248 pg/mL vs. $2901 \mathrm{pg} / \mathrm{mL}, p=0.0013)$ and Tmax later (130 mins. vs. 77 mins., $p=0.0003)$, with a lower AUC (350k vs. 414k, $p<0.0001$ ) and lower maximum rise over baseline $(518 \mathrm{pg} / \mathrm{mL}$ vs. $1235 \mathrm{pg} / \mathrm{mL}, p=$ 0.0002) (see Fig. 3c). The final rise over baseline was higher for DRN than UN but not significantly $(319 \mathrm{pg} / \mathrm{mL}$ vs. $172 \mathrm{pg} / \mathrm{mL}, p=0.08)$.

Slopes $(\mathrm{pg} / \mathrm{mL} / \mathrm{min})$ for DRN were positive in the first $90 \mathrm{~min}$ (DRN $\left.\beta_{1}=2.31 \mathrm{pg} / \mathrm{mL} / \mathrm{min}, \quad p=0.035\right)$ and negative in the last $90 \mathrm{~min}$ for $\mathrm{UN}\left(\beta_{1}=-8.40, p<\right.$ $0.0001)$. Slopes differed significantly between DRN and $\mathrm{UN}$ in last $90 \mathrm{~min}(p<0.0001)$. Within-group comparisons of slope between the first and last $90 \mathrm{~min}$ were not significant for DRN $(p=0.26)$.

\section{Insulin}

Insulin C-max was lower following DRN than following UN (1439 pg/mL vs. $2196 \mathrm{pg} / \mathrm{mL}, p=0.0003)$ and Tmax was later following DRN than following UN (111 mins. vs. 59 mins, $p<0.0001)$, along with a lower AUC (216k vs. $269 \mathrm{k}, p=0.0005)$, a lower maximum rise over baseline (395 pg/mL vs. $1201 \mathrm{pg} / \mathrm{mL}, p=0.0001)$, and a greater final increase over baseline $(187 \mathrm{pg} / \mathrm{mL}$ vs. $20 \mathrm{pg} / \mathrm{mL}, p=$ 0.0042) (see Fig. 3d).

Slopes $(\mathrm{pg} / \mathrm{mL} / \mathrm{min}$ ) for UN negative in the last $90 \mathrm{~min}$ $\left(\beta_{1}=-6.68, p<0.0001\right)$, with no significant difference from zero in either period for DRN. Slopes differed significantly between DRN and UN in last $90 \mathrm{~min}(p<$ 0.0001). Within-group comparisons of slopes between first and last $90 \mathrm{~min}$ were not significant for DRN $(p=0.48)$. 


\section{Satiety and adverse effects}

Seven measures were evaluated at 14 time points at each MTT, with only two significant differences identified between DRN and UN. The lowest hunger score was earlier for DRN than UN (19 mins. vs. 44 mins, $p=$ 0.0155). The maximum score for satisfaction was lower for DRN than UN $(p=0.0125)$. There was also a significant visit effect for satisfaction in that peak satisfaction occurred $28 \mathrm{~min}$ later at visit 1 than visit 2 , regardless of treatment (DRN vs. UN).

\section{Discussion}

Our overall aim is to formulate a nutrient that induces appetite and glucose control of therapeutic value via activation of a variety of neurohormonal intestinal pathways, including increased release of GLP-1 due to rapid release of nutrient in the upper small intestine. The formulation we developed met our particle size and in vitro $\mathrm{pH}$ and temporal release specifications. However, the effects on appetite and gut hormones were not similar to those seen following enteral feeding tube studies for uncertain reasons. There was, however, a delayed rise in GLP-1 with formulated nutrient, with levels still rising at the end of the 3-h study window.

Studies using an enteral feed tube to administer different doses of nutrient to the intestine support our strategy of using delayed-release nutrient to induce appetite and glucose control ${ }^{6-8}$. We previously demonstrated that $250 \mathrm{kcals}$ of mixed nutrient delivered directly to the upper small intestine by feeding tube rapidly induces a rise in GLP-1 and satiety ${ }^{6}$. To administer a similar amount of nutrient in an orally ingested formulated version without concern for toxicity we used a GRAS coating. By contrast Ma et al. administered two doses of lauric acid with a far lower caloric load $(22.5 \mathrm{kcal})$ coated in methacrylic acid-methyl methacrylate copolymer, a non-GRAS coating (Eudragit L100; Evonik Industries AG, Darmstadt, Germany) at two sequential meals ${ }^{13}$. The authors demonstrated that GLP1 was higher and glucose lower after the second dose of coated nutrient compared with placebo. Effects on appetite were not reported. The dose of coating material used by Ma et al. was at the upper approved limit for daily intake, which could limit long-term use.

In the recent publication by Alleleyn et al. ${ }^{16}$, all-natural particles of similar size and nutrient composition to those used in the current study but with a modified whey coating were formulated with the goal of increasing nutrient delivery to the distal ileum in order to activate the ileal brake. A small but significant increase in satiety and decrease in hunger was seen by $15 \mathrm{~min}$ after ingestion compared with a control nutrient and similarly there was a there was a small reduction in caloric intake of a subsequent ad libitum meal.
In the current study, unformulated nutrient showed the expected significant rise in glucose and hormones over the first hour and then fall to baseline by the end of the 3$h$ study. By contrast, maximal levels following the delayed-release nutrient occurred later, and were lower, except for GLP-1, which continued to rise at $3 \mathrm{~h}$. Furthermore, measures of hormones, with delayed-release nutrient for glucose and appetite were lower than those seen following delivery of a similar caloric load to the upper intestine by enteral feeding tube and gastric bypass ${ }^{6-8,25}$.

Given that we did not directly measure when, where, and how much nutrient was released we do not know why appetite and hormonal changes differed from those hypothesized based on in vitro testing. We propose several possible reasons for our findings.

Firstly, the 3-h meal tolerance test might have been too short to allow for maximum nutrient release and effect on GLP-1, appetite, and other outcome measures. The GRAS nutrient formulation used in the clinical study had in vitro dissolution characteristics suggesting that the majority of the nutrient load would be released in vivo in the small intestine within $3 \mathrm{~h}$ of ingestion. However, non-sucrose nutrient release from the particles may not have occurred at the rate observed in the in vitro dissolution testing, which measured only sucrose release. Morphological changes may have occurred in the formulated nutrient in the gastrointestinal tract that altered the coating, or core nutrient release. For example, swelling of ethyl cellulose may have prevented $\mathrm{pH}$-dependent alginate pore formation and nutrient release.

Secondly, gastric emptying may have been slower than expected. We hypothesized that the 2-mm particles would pass through the stomach at the rate of plain water ${ }^{20}$. The particles may, however, have sedimented in the stomach of the semi-recumbent subjects ${ }^{27}$. It is also possible that as nutrient, gastric acid, and quinine from the tonic water were released into the intestine, they slowed gastric emptying delaying intestinal delivery of the full caloric load $^{28,29}$. This slowing of nutrient delivery is not present when nutrient is administered by enteral feeding tube or following gastric bypass ${ }^{30,31}$.

Some formulated nutrient may have passed through unabsorbed to the large intestine. In this case symptoms such as bloating, or diarrhea may have occurred. However, no such symptoms were reported by the subjects.

A limitation of this study is that the site, length, and rate of nutrient exposure, that determine hormonal and appetite effect of nutrient, were not assessed ${ }^{32}$. In vitro gastrointestinal simulation testing is not readily available, is poorly standardized, and correlation with human testing weak ${ }^{33}$. All methods have several drawbacks including radiation exposure, limited temporal resolution, and failure to distinguish between various gastrointestinal 
segments ${ }^{34}$. Labeling the active ingredient with drugs or radioisotopes is not permitted at food (GMP) manufacturing facilities. We did not add coating markers of gut transit and absorption after production as there was no evidence that the marker would transit the intestine with the nutrient particles. Lactulose as used in hydrogen breath testing may accelerate small bowel transit. Furthermore, marker coatings might alter nutrient release from the particles and could also be hazardous to the research team and subjects. Iterative in vitro formulation modification and in vivo testing was considered to be the most pragmatic developmental strategy. An ad libitum meal is a feasible means of assessing any effect on total caloric intake ${ }^{16}$.

The tonic water used to ingest the nutrients contains quinine may have altered gut hormone release and appetite $^{35,36}$. However, as the same solution was used with both meals differences between the groups are unlikely to be due to the quinine.

We assume that several macronutrients stimulated GLP-1 release, and that both nutrient and GLP-1 stimulated c-peptide release. This might explain why peak insulinemia with UN corresponds to a blood glucose peak rather than follows it as might be expected following glucose administration. While GLP-1 levels rise late in the study following DRN administration this is not associated with a rise in insulin. This may be because threshold levels of GLP-1, nutrient and glycemia needed to stimulate insulin release were not achieved.

With respect to limitations of the statistical analysis, the large number of statistical comparisons could be considered a limitation in interpretation of results. However, where there was a significant difference between modes, the $p$-values tended to be very small, so testing at a smaller significance level, e.g., $p<0.01$ or even 0.005 would only affect three results: Glucose AUC, GLP-1 Tmax, and GLP-1 final-initial would no longer be significant.

This work provides additional information regarding the use of formulated nutrient for appetite and glucose control. The formulation we evaluated was comprised of ingredients that are widely consumed. The dietary fiber coating may provide health benefits ${ }^{37-39}$. The findings of this study may be generalizable to other obese adults with type 2 diabetes. It is possible that the study subjects who had type 2 diabetes could have had altered gastrointestinal motility that could have affected findings and that would not be expected to be present in obese adults without diabetes.

Numerous areas in the field of targeted enteral nutrient require further study. Testing this formulation for a longer period and with multiple doses in ambulatory subjects would provide a more complete picture of the GLP-1 profile and effects on appetite. The formulation may be modified to provide a higher caloric load and different nutrient cores and coatings. Future studies will adjust the experimental design to focus on outcome measures for either appetite and caloric intake, or glycemic control, rather than both.

\section{Conclusion}

This study explores the use of formulated nutrient to control appetite and dysglycemia. It adds to the limited published research by presenting data on the use of a novel delayed-release natural coating to deliver nutrient directly to the intestine in obese adults with type 2 diabetes. Findings demonstrate that GLP-1 release can be delayed with this strategy, but further work is needed to develop an optimal formulation that achieves the desired effects on gut hormones and appetite. We have identified several areas for further research including options for modifying the nutrient formula, and the development of more widely available and feasible methods of assessing gastrointestinal transit and nutrient absorption in humans.

\section{Acknowledgements \\ This publication was funded by the USC Coulter Translational Research \\ Program USC and by grants UL1TR001855 and UL1TR000130 from the National Center for Advancing Translational Science (NCATS) of the U.S. National \\ Institutes of Health. The content is solely the responsibility of the authors and does not necessarily represent the official views of the National Institutes of Health. \\ Author details \\ ${ }^{1}$ Division of Endocrinology and Diabetes, Keck School of Medicine, University of Southern California, Los Angeles, CA 90033, USA. ${ }^{2}$ SC CTSI, Keck School of Medicine, University of Southern California, Los Angeles, CA 90033, USA. ${ }^{3}$ CaliVive Inc., San Mateo, CA 94402, USA \\ Conflict of interest \\ The authors declare that they have no conflict of interest.}

\section{Publisher's note}

Springer Nature remains neutral with regard to jurisdictional claims in published maps and institutional affiliations.

\section{Appendix A}

\section{Details of visual analog score}

Subjects were asked "How hungry do you feel?", "How full do you feel?", "How satisfied do you feel?" and "How much do you think you can eat now?". The scales were anchored at either end by statements; "I am not hungry at all/I am not full at all/I am completely empty/nothing at all" on the left and "I am as hungry as I have ever been/I am totally full/I cannot eat another bite/a large amount" on the right. Adverse symptom questions were anchored at either end by statements; "I have no nausea/abdominal pain/perspiration/palpitations at all" on the left and "I have a lot of nausea/ abdominal pain/perspiration/palpitations" on the right. 


\section{Appendix B}

Intervention means and mean differences for delayed-relase (DRN) vs. unformulated nutrient (UN)

\begin{tabular}{|c|c|c|c|c|c|}
\hline Measure & DRN: Mean (SE) & UN: Mean (SE) & Mean difference: DRN minus UN (SE) & 95\% confidence interval & $p$-value \\
\hline \multicolumn{6}{|l|}{ GLP-1 (pg/mL) } \\
\hline Cmax & $192.89(12.75)$ & $194.88(12.75)$ & $-1.99(10.75)$ & $(-24.68,20.70)$ & 0.86 \\
\hline Tmax (minutes) & $103.23(13.17)$ & $57.82(13.17)$ & $45.42(18.64)$ & $(6.08,84.75)$ & 0.026 \\
\hline AUC & 29177 (1872.38) & $29884(1872.38)$ & $-706.39(1085.50)$ & $(-2996.60,1583.81)$ & 0.52 \\
\hline Maximum rise over Baseline & $32.53(6.78)$ & $39.06(6.78)$ & $-6.52(9.59)$ & $(-26.76,13.71)$ & 0.51 \\
\hline Final-initial & $11.55(5.69)$ & $-8.71(5.69)$ & $20.26(7.88)$ & $(3.63,36.89)$ & 0.02 \\
\hline \multicolumn{6}{|l|}{ Glucose (mg/dL) } \\
\hline Cmax & $142.20(8.49)$ & $167.61(8.49)$ & $-25.41(5.01)$ & $(-35.98,-14.84)$ & $<0.0001$ \\
\hline Tmax (minutes) & $84.01(9.0)$ & $43.09(9.0)$ & $40.92(11.85)$ & $(15.91,65.92)$ & 0.003 \\
\hline AUC & $23997(1489.44)$ & $26021(1489.44)$ & $-2024.18(775.18)$ & $(-3659.66,-388.69)$ & 0.018 \\
\hline Maximum rise over Baseline & $11.94(2.68)$ & $35.34(2.68)$ & $-23.40(3.10)$ & $(-29.94,-16.86)$ & $<0.0001$ \\
\hline Final-initial & $1.10(3.07)$ & $-9.41(3.07)$ & $10.51(3.63)$ & $(4.96,16.05)$ & 0.0009 \\
\hline \multicolumn{6}{|l|}{ Insulin (pg/mL) } \\
\hline Cmax & 1439.09 (162.84) & $2195.78(162.84)$ & $-756.69(167.20)$ & $(-1109.45,-403.93)$ & 0.0003 \\
\hline Tmax (minutes) & $111.10(6.64)$ & $59.43(8.64)$ & 51.67 (9.92) & $(30.74,72.60)$ & $<0.0001$ \\
\hline AUC & 216417 (19563) & 268827 (19563) & $-52410(12316)$ & $(-78395,-26425)$ & 0.0005 \\
\hline Maximum rise over Baseline & $394.77(141.31)$ & $1201.28(141.31)$ & $-806.51(161.34)$ & $(-1146.91,-466.11)$ & 0.0001 \\
\hline Final-initial & $186.80(38.52)$ & $19.87(38.52)$ & $166.93(50.57)$ & $(60.25,273.62)$ & 0.0042 \\
\hline \multicolumn{6}{|l|}{ C-Peptide (pg/mL) } \\
\hline Cmax & $2248.24(185.17)$ & $2901.81(185.17)$ & $-653.57(170.23)$ & $(-1012.71,-294.42)$ & 0.0013 \\
\hline Tmax (minutes) & $129.84(9.23)$ & $77.04(9.23)$ & $52.83(11.66)$ & $(28.23,77.43)$ & 0.0003 \\
\hline AUC & 349525 (21166) & 413522 (21166) & $-63997(11926)$ & $(-89159,-38835)$ & $<0.0001$ \\
\hline Maximum rise over baseline & $517.76(147.05)$ & $1235.28(147.05)$ & $-717.52(151.96)$ & $(-1038.12,-396.92)$ & 0.0002 \\
\hline Final-initial & 318.97 (61.47) & $171.83(61.47)$ & 147.14 (79.32) & $(-20.21,314.49)$ & 0.08 \\
\hline
\end{tabular}

$P$-values from linear mixed effects model for crossover design

Received: 3 October 2018 Revised: 27 May 2019 Accepted: 13 June 2019 Published online: 15 July 2019

\section{References}

1. Jacobsen, S. H. et al. Effects of gastric bypass surgery on glucose absorption and metabolism during a mixed meal in glucose-tolerant individuals. Diabetologia 56, 2250-4 (2013).

2. Laferrère, B. Effect of gastric bypass surgery on the incretins. Diabetes Metab. 35(6 Pt 2), 513-7 (2009).

3. Abdeen, G. \& C. W. le Roux, Mechanism Underlying the Weight Loss and Complications of Roux-en-Y Gastric Bypass. Review. Obes. Surg. 26, 410-21 (2016).

4. Seeley, R. J., Chambers, A. P. \& Sandoval, D. A. The role of gut adaptation in the potent effects of multiple bariatric surgeries on obesity and diabetes. Cell Metab. 21, 369-78 (2015).

5. Smith, E. P. et al. Altered glucose metabolism after bariatric surgery: What's GLP-1 got to do with it?. Metabolism 83, 159-166 (2018). p.
6. Beale, E., Walker, M, Karapetyan A, Lee W, lonut, V. A Well-Tolerated Mixed Macronutrient Meal Delivered Directly to the Upper Intestine via Enteral Feeding Tube Acutely and Significantly Enhances Glucoregulatory and Anorectic Hormone Release in Adults with Obesity and T2D [Poster]. in The Obesity Society Annual Meeting at Obesity Week 2016. New Orleans, LA (2016).

7. Beale E, L. W., Ge, M, lonut V. Delivery of Nutrient Directly to the Upperintestine Enhances the Release of Endogenous Incretins in Type 1 Diabetes., in 99th Annual Meeting of the Endocrine Society. Orlando, FL (2017).

8. Alleleyn, A. M. et al. Gastrointestinal Nutrient Infusion Site and Eating Behavior: Evidence for A Proximal to Distal Gradient within the Small Intestine? Nutrients 8, 117 (2016).

9. Welch, I. M., Sepple, C. P. \& Read, N. W. Comparisons of the effects on satiety and eating behaviour of infusion of lipid into the different regions of the small intestine. Gut 29, 306-11 (1988).

10. Batterham, R. L. \& Cummings, D. E. Mechanisms of Diabetes Improvement Following Bariatric/Metabolic Surgery. Diabetes Care 39, 893-901 (2016).

11. Czarnocka, J. K. \& Alhnan, M. A. Gastro-resistant characteristics of GRAS-grade enteric coatings for pharmaceutical and nutraceutical products. Int J. Pharm. 486, 167-74 (2015). 
12. Chan, Y. K. et al. The emulsified lipid Fabuless (Olibra) does not decrease food intake but suppresses appetite when consumed with yoghurt but not alone or with solid foods: a food effect study. Physiol. Behav. 105, 742-8 (2012).

13. $\mathrm{Ma}$, J. et al. A randomised trial of enteric-coated nutrient pellets to stimulate gastrointestinal peptide release and lower glycaemia in type 2 diabetes. Diabetologia 56, 1236-42 (2013).

14. Geraedts, M. C. et al. Intraduodenal administration of intact pea protein effectively reduces food intake in both lean and obese male subjects. PLoS One 6, e24878 (2011)

15. Corstens, M. N. et al. Food-grade micro-encapsulation systems that may induce satiety via delayed lipolysis: a review. Crit. Rev. Food Sci. Nutr. 57, 2218-2244 (2017).

16. Alleleyn, A. M. E. et al. The effect of an encapsulated nutrient mixture on food intake and satiety: a double-blind randomized cross-over proof of concept study. Nutrients 10, 1787 (2018).

17. FDA. Generally Recognized as Safe (GRAS). http://www.fda.gov/Food/ IngredientsPackagingLabeling/GRAS/ (2018).

18. WHO. Acceptable daily intakes, other toxicological information, and information on specifications; WHO FOOD ADDITIVES SERIES: 50 ANNEX 4. http:// www.inchem.org/documents/jecfa/jecmono/v50je19.htm (2016).

19. Herrman, J. L. \& Younes, M. Background to the ADI/TDI/PTWI. Regul. Toxicol. Pharm. 30(2 Pt 2), S109-13 (1999).

20. Siegel, J. A. et al. Biphasic nature of gastric emptying. Gut 29, 85-9 (1988).

21. Cunningham, $C$. et al. Evaluation of recent advances in continuous film coating processes. Drug Dev. Ind. Pharm. 36, 227-33 (2010).

22. Poppitt, S. D. et al. Investigating acute satiation and meal termination effects of a commercial lipid emulsion: A breakfast meal study. Physiol. Behav. 152(Pt A), 20-5 (2015).

23. Blundell, J. Making claims: functional foods for managing appetite and weight. Nat. Rev. Endocrinol. 6, 53-6 (2010).

24. Flint, A. et al. Reproducibility, power and validity of visual analogue scales in assessment of appetite sensations in single test meal studies. Int J. Obes. Relat. Metab. Disord. 24, 38-48 (2000)

25. Jacobsen, S. H. et al. Changes in gastrointestinal hormone responses, insulin sensitivity, and beta-cell function within 2 weeks after gastric bypass in nondiabetic subjects. Obes. Surg. 22, 1084-96 (2012).
26. Harris, P. A. et al. Research electronic data capture (REDCap)-a metadata-driven methodology and workflow process for providing translational research informatics support. J. Biomed. Inf. 42, 377-81 (2009).

27. Holwerda, A. M. et al. Body position modulates gastric emptying and affects the post-prandial rise in plasma amino acid concentrations following protein ingestion in humans. Nutrients 8, 221 (2016).

28. Holst, J. J. et al. Roles of the gut in glucose homeostasis. Diabetes Care 39, 884-92 (2016).

29. Lin, H. C. et al. Inhibition of gastric emptying by acids depends on $\mathrm{pH}$, titratable acidity, and length of intestine exposed to acid. Am. J. Physiol. 259(6 Pt 1), G1025-30 (1990).

30. Nguyen, N. Q. et al. Effects of fat and protein preloads on pouch emptying, intestinal transit, glycaemia, gut hormones, glucose absorption, blood pressure and gastrointestinal symptoms after Roux-en-Y gastric bypass. Obes. Surg. 26 77-84 (2016).

31. Melissas, J. et al. Alterations of global gastrointestinal motility after sleeve gastrectomy: a prospective study. Ann. Surg. 258, 976-82 (2013).

32. Little, T. J. et al. The release of GLP-1 and ghrelin, but not GIP and CCK, by glucose is dependent upon the length of small intestine exposed. Am. J. Physiol. Endocrinol. Metab. 291, E647-55 (2006).

33. Kostewicz, E. S. et al. In vitro models for the prediction of in vivo performance of oral dosage forms. Eur. J. Pharm. Sci. 57, 342-66 (2014).

34. Grønlund, D. et al. Established and emerging methods for assessment of small and large intestinal motility. Neurogastroenterol. Motil. 29, 13008 (2017).

35. van Avesaat, $\mathbf{M}$. et al. Intraduodenal infusion of a combination of tastants decreases food intake in humans. Am. J. Clin. Nutr. 102, 729-35 (2015).

36. Klaassen, $\mathrm{T}$. et al. Intraintestinal delivery of tastants using a naso-duodenal-ileal catheter does not influence food intake or satiety. Nutrients. 11, 472 (2019).

37. Dahl, W. J. \& Stewart, M. L. Position of the Academy of Nutrition and Dietetics: health implications of dietary fiber. J. Acad. Nutr. Diet. 115, 1861-70 (2015).

38. Georg Jensen, M., Kristensen, M. \& Astrup, A. Effect of alginate supplementation on weight loss in obese subjects completing a 12-wk energyrestricted diet: a randomized controlled trial. Am. J. Clin. Nutr. 96, 5-13 (2012).

39. Georg Jensen, M. et al. Review: efficacy of alginate supplementation in relation to appetite regulation and metabolic risk factors: evidence from animal and human studies. Obes. Rev. 14, 129-44 (2013). 